\title{
The Composition and Structure of Lymph Chylomicrons in Dog, Rat, and Man*
}

\author{
D. B. Zilversmit $\dagger$ \\ (From the Department of Physiology and Biophysics, University of Tennessee Medical Units, \\ Memphis, Tenn.)
}

The removal of chylomicrons from the blood stream has been studied by many investigators (1). Studies with isotopically labeled lipids have revealed that the liver removes a large portion of injected chylomicrons and that this organ takes up intact lipid particles from blood. Similar studies on adipose tissue have revealed that hydrolysis takes place before tissue uptake. The removal of chylomicrons has been compared to the removal of fat particles from artificial fat emulsions. Some of the latter are taken up predominantly by Kupffer cells of the liver, whereas the former go primarily to the liver parenchyma $(2,3)$.

Possibly a study of chylomicron structure might elucidate the physiological behavior of these particles, but thus far little or no direct studies on structure have been made although models have been postulated on the basis of known physicochemical properties of the various chylomicron constituents (1). Recent publications from our laboratory have shown that the percentages of cholesterol, cholesterol ester, phospholipid, and protein are roughly proportional to the surfacevolume ratios of different sized chylomicrons. This might indicate that these constituents occur primarily on the surface of a triglyceride droplet (4). Parallel studies of plasma lipoproteins showed, however, that at a heptane-water interface these proteins lose their cholesterol and cholesterol ester to the heptane phase (5). It would seem reasonable, therefore, that at the oil-water interface of a chylomicron some or all of the

\footnotetext{
* Submitted for publication April 29, 1965; accepted June 16, 1965.

Supported by grant HE-01238 from the National Heart Institute, U. S. Public Health Service.

+ Career Investigator of the American Heart Association.

Address requests for reprints to Dr. D. B. Zilversmit, Dept. of Physiology and Biophysics, University of Tennessee, Memphis, Tenn. 38103.
}

sterol might be dissolved in the oil phase of the droplet. The present investigation was designed to study the distribution of various lipids between the interior and the surface of the chylomicron.

\section{Methods}

Preparation of chylomicrons. Mongrel dogs of both sexes, fasted overnight, were fed about $100 \mathrm{ml}$ of $36 \%$ fat in the form of whipping cream or of corn oil emulsified in skim milk. Thoracic duct lymph was collected in iced containers from anesthetized animals immediately after cannulation for periods up to 10 hours or in unanesthetized animals during intervals beginning 24 hours after surgery and extending for 3 or 4 days. Rats were cannulated in the cisterna chyli, and lymph was collected from unanesthetized, restrained animals starting the day after surgery. The animals were fed $1 \mathrm{ml}$ of cream periodically or the equivalent amount of corn oil. The patient 1 was a 43-year-old Negro man known to have had diabetes mellitus for at least 3 years. Admission to the hospital was because of a right axillary abscess with bleeding from this site. On admission the serum triglyceride level was $20 \mathrm{~g}$ per $100 \mathrm{ml}$, and the total cholesterol was $1.9 \mathrm{~g}$ per $100 \mathrm{ml}$. Surgical drainage of the abscess was carried out, and at the time the thoracic duct was cannulated (6). Several days later the patient received a single feeding of $100 \mathrm{~g}$ of fat in the form of heavy cream, and lymph was collected for 24 hours. A similar amount of corn oil was then given and lymph collected for 24 hours.

The chyle was defibrinated by gentle stirring with a wooden applicator stick and filtered through gauze. The filtrate was then centrifuged in a swinging bucket rotor at $25,000 \mathrm{rpm}$ (average $g=53,000$ ) for $\frac{1}{2}$ to 1 hour at $10^{\circ}$ C. The packed layer of chylomicrons was removed with a spatula; the chylomicrons were resuspended in $0.9 \%$ $\mathrm{NaCl}$ and recentrifuged as before. Washing with saline was repeated once more after which an additional wash with water was performed. The last wash with water removed the salt that would have interfered with total lipid determinations and with the digestion of protein. Lymph subnatant, essentially free from chylomicrons, was

1 Data supplied by H. J. Kayden, Department of Medicine, New York University School of Medicine. Dr. Kayden generously furnished the lymph, which was air mailed to Memphis in iced containers. 
obtained from the bottom layer of the first centrifugation of chyle.

Preparation of oil and membrane. Washed chylomicrons, either suspended in water or as a compact buttery layer, were frozen in the freezing compartment of a refrigerator at $-40^{\circ} \mathrm{C}$. After thorough freezing, usually overnight, the tubes were warmed slowly to room temperature. In the case of chylomicrons collected after corn oil feeding, some oil droplets on the surface were visible at this time. To prepare sufficient membrane for chemical analysis, the thawed preparation was refrozen and thawed a number of times. In the case of corn oil chylomicrons, three or four cycles of freezing and thawing usually sufficed to liberate a layer of oil several millimeters thick. In the case of cream chylomicrons, repeated freezing and heating to temperatures up to $40^{\circ} \mathrm{C}$ set free only a few small drops of oil.

To the thawed preparation was added 10 to $15 \mathrm{ml}$ of water, and the oil phase was separated from the subnatant by low speed centrifugation. The oil was then washed several times with additional water and centrifuged to remove adhering intact chylomicrons. The aqueous subnatant was subjected to ultracentrifugation at $100,000 \mathrm{~g}$. After 20 minutes a pellet was seen in the bottom of the tube. Additional high speed centrifugation for 24 hours sedimented more material in pellet form. Dispersion of the pellet in water and recentrifugation did not produce any loss of phospholipid or cholesterol. Electron micrographs were prepared from sections of the two pellets fixed in glutaraldehyde, then fixed with osmium tetroxide, and stained with uranyl acetate and lead hydroxide. ${ }^{2}$

Chemical procedures. Chylomicron or membrane fractions were extracted with ethanol-ethyl ether (3/1, vol/ vol), which was brought to a boil. The protein was allowed to precipitate overnight at $4^{\circ} \mathrm{C}$ since a previous study had shown that under these conditions little or no protein remained in the extract (4). After centrifugation and washing with ethanol-ethyl ether followed by ether, the precipitate was stored in the deepfreeze for subsequent analysis of total amino nitrogen (7). The alcohol ether extract was evaporated under vacuum and the residue picked up in chloroform. A sample was evaporated in vacuo for total lipid determination by weighing. $U_{p}$ to $10 \mathrm{mg}$ of lipid was applied to a $1-\mathrm{g}$ silicic acid-Super-Cel (1/1) column for separation of "neutral" lipids and phospholipids with chloroform and methanol as eluants (8). Subsequent separation of cholesterol esters was performed on a similar column with $10 \%$ chloroform in petroleum ether used to elute the esters and chloroform to elute the rest (8). All column fractionations were checked for purity by applying small samples of the eluates to thin layer silica gel $G$ plates that were developed with petroleum ether-ether-acetic acid $(80 / 20 / 1, \mathrm{vol} / \mathrm{vol} / \mathrm{vol})$ for neutral lipids or chloroform-methanol-water $(140 / 50 / 9$, vol/vol/vol $)$ for phospholipids. Lipid spots were visualized by charring after spraying the plate with $\mathrm{H}_{2} \mathrm{SO}_{4}$ and illuminating it with

2 The author wishes to thank Dr. A. J. Ladman for preparation of the electron micrographs. ultraviolet light. In this manner very minute contaminations of lipid fractions could be detected. Columns were rerun when separations were incomplete as judged by thin layer chromatography.

Appropriate lipid fractions were saponified with $4 \%$ alcoholic $\mathrm{KOH}$ at $65^{\circ} \mathrm{C}$ for 1 hour, and cholesterol was determined on a petroleum ether extract with the $\mathrm{FeCl}_{3}$ $\mathrm{H}_{2} \mathrm{SO}_{4}$ reagent described by $\mathrm{Zak}$, Moss, Boyle, and Zlatkis (9). Total phospholipid phosphorus was determined after digestion with $\mathrm{H}_{2} \mathrm{SO}_{4}$ by the method of Bartlett (10). Glycerides were determined by saponification and determination of glycerol by the following modification of the periodate oxidation technique described by Van Handel and Zilversmit (11). After saponification of the silicic acid column eluate containing the glycerides and free cholesterol with $0.4 \%$ alcoholic $\mathrm{KOH}$, the mixture was acidified with $0.2 \mathrm{~N} \mathrm{H}_{2} \mathrm{SO}_{4}$, and cholesterol and free fatty acids were removed by a single extraction with petroleum ether. After removing nearly all of the ether phase with a transfer pipette, the rest of the petroleum ether was evaporated in a water bath at $60^{\circ} \mathrm{C}$. After oxidation with $\mathrm{NaIO}_{4}$ as described before, the excess oxidizing agent was reduced with $5 \% \quad \mathrm{NaHSO}_{3}$. Heating with chromotropic acid was carried out as described before, but after cooling the mixture $0.2 \mathrm{ml}$ of $10 \%$ aqueous thiourea was added to remove iodine liberated during heating. This step reduced the reagent blank to less than half of that obtained by the original procedure.

Individual phospholipid fractions were separated from phospholipids eluted off the silicic acid column by thin layer chromatography with silica gel $G$ containing Ultraphor for visualization of lipid spots (12). Methyl esters of lipid fractions were prepared by heating the thin layer plate scrapings with $2 \% \mathrm{H}_{2} \mathrm{SO}_{4}$ in methanol at $65^{\circ} \mathrm{C}$ overnight, except in the case of sphingomyelin, for which $5 \% \mathrm{H}_{2} \mathrm{SO}_{4}$ was employed (13). Total phospholipid fatty acid patterns determined on silicic acid column eluates showed good agreement with those obtained from thin layer plates. Chromosorb $\mathrm{W}$ coated with $14 \%$ polyethylene glycol adipate ester was obtained commercially. ${ }^{3}$ Six-foot spiral glass columns of $4 \mathrm{~mm}$ i.d. were operated at $190^{\circ} \mathrm{C}, 15$ pounds per square inch inlet pressure, and flow rate of $60 \mathrm{ml}$ argon per minute. The eluant was monitored by an argon ionization chamber containing a tritium source. NIH standards A-E were used to establish the operating parameters. The composition, calculated from peak height times retention time, was found to agree with standards $\mathrm{B}$ and $\mathrm{D}$ to within $11 \%$ for peaks less than $5 \%$ of the total and within $6 \%$ for peaks greater than $5 \%$, the errors being the arithmetic mean, without regard to sign, of the relative percentage deviations from the standard. In Tables $\mathrm{V}$ to IX the total percentage does not add up to 100 since minor components have been omitted from the Tables.

Radioactive digitonin labeled with $\mathrm{H}^{3}$ was extensively purified by precipitation with cholesterol.4 About 0.1

\footnotetext{
3 Applied Science, State College, $\mathrm{Pa}$.

4 Kindly given to us by Dr. M. Morris, Department of Pediatrics, University of Arkansas Medical College, Little Rock, Ark.
} 
$\mathrm{ml}$ washed chylomicrons containing 10 to $15 \mathrm{mg}$ lipid was incubated with $0.5 \mathrm{ml} 0.08 \%$ aqueous $\mathrm{H}^{8}$-digitonin at room temperature overnight. The chylomicrons were separated by centrifugation in a salt gradient (8) at $50,000 \mathrm{~g}$ for 1 hour. Tritiated digitonin bound to chylomicrons was determined in a liquid scintillation counter. A portion of the aqueous $\mathrm{H}^{3}$-digitonin was dried at room temperature under vacuum, dissolved in $50 \%$ aqueous alcohol, and added in large excess to cholesterol dissolved in acetone alcohol (1/1) according to the procedure of Morris (14). After dissolving, reprecipitation, and washing of the precipitate the cholesterol digitonide was dissolved in a small volume of absolute methanol; one sample was counted and another used for cholesterol analysis. From the radioactivity bound to a known amount of chylomicrons and the $\mathrm{H}^{3}$-digitonin activity per milligram of cholesterol standard, the amount of free cholesterol on the surface of the chylomicron was estimated. This assumes, of course, that $a$ ) all the free cholesterol on the chylomicron surface binds digitonin in the same proportion as in alcohol acetone in which the cholesterol standards were dissolved, $b$ ) no other component on the chylomicron surface binds digitonin, and c) no digitonin penetrates into the oil phase of the chylomicrons.

\section{Results}

Validity of oil-membrane separations. Several procedures were found to liberate oil from corn oil chylomicrons. In addition to the freezing and thawing described in the Methods section, lyophilization, immersion of a chylomicron sample in boiling water for 5 minutes, or dehydration under vacuum in a rotary evaporator was found to liberate appreciable amounts of oil. Even centrifugation at $50,000 \mathrm{~g}$ for 30 minutes employed for the harvesting and washing of chylomicrons set free visible oil droplets on the surface.

For practical reasons we used the freeze-thaw procedure to prepare membrane and oil for chemical analysis. It is possible, of course, that the repeated freezing and thawing might shift certain

TABLE I

Percentage of chylomicron free cholesterol in membrane

\begin{tabular}{cccc}
\hline & \multicolumn{3}{c}{ Method* } \\
\cline { 2 - 4 } Dog & A & B & C \\
\hline & $\%$ & $\%$ & $\%$ \\
19 & 64.0 & 66.5 & 71.5 \\
24 & 68.1 & 67.1 & 77.8
\end{tabular}

* A, calculated from FC (free cholesterol) in membrane and oil fractions; B, calculated from FC/TG (triglyceride) in oil and whole chylomicron; $\mathrm{C}$, calculated from $\mathrm{H}^{3}-$ digitonin. lipids between membrane and oil phase. We therefore attempted to evaluate this possibility for free cholesterol, which was present in the oil as well as the membrane fraction.

One sample of a washed corn oil chylomicron preparation was frozen and thawed four times, after which oil and membrane were separated by the method described previously except that great care was taken to recover the oil and membrane fractions as nearly quantitatively as possible. The ratio of free cholesterol in membrane and oil was calculated from a direct comparison of the amounts of cholesterol in these fractions. Since we did not know whether recovery of membrane fraction was quantitative, an alternative calculation was based on the following formulas: free cholesterol (FC) in membrane $=\mathrm{FC}$ in whole chylomicron $-\mathrm{FC}$ in oil. Since nearly all the triglyceride (TG) is in the oil phase of the chylomicrons, one may divide as follows:

$\mathrm{FC}$ in membrane

TG in whole chylomicron

$$
=\frac{\mathrm{FC} \text { in whole chylomicron }}{\mathrm{TG} \text { in whole chylomicron }}-\frac{\mathrm{FC} \text { in oil }}{\mathrm{TG} \text { in oil }} .
$$

The ratios on the right-hand side are independent of quantitative recovery of oil phase or membrane. Thus we calculate the quantity on the left and have per cent of $\mathrm{FC}$ in membrane $=$

$\mathrm{FC}$ in membrane/TG

in whole chylomicron
FC in whole chylomicron/TG
in whole chylomicron

A third estimate of the per cent of FC in membrane is calculated from the amount of $\mathrm{H}^{3}$-digitonin bound to intact washed chylomicrons with a known free cholesterol content.

A comparison of the percentage of chylomicron free cholesterol present in the membrane calculated by the three methods is shown in Table I. The reasonable correspondence between the values derived from separating oil and membrane by freezing and those obtained by incubation with $\mathrm{H}^{3}$-digitonin indicates that the disruption of chylomicrons by freezing does not materially alter the distribution of cholesterol between membrane and oil phase.

Composition of chylomicron oil and membrane. Table II summarizes the lipid and protein com- 
TABLE II

Lipids of dog lymph chylomicrons, oil, and membrane*

\begin{tabular}{|c|c|c|c|c|c|}
\hline Dog & Fraction & Triglyceride† & Phospholipid $†$ & Cholesterol† & Protein $\ddagger$ \\
\hline 10 & $\begin{array}{l}\text { Chylomicron } \\
\text { Oil }\end{array}$ & $\begin{array}{c}\% \\
96.0 \\
99.3\end{array}$ & $\begin{array}{c}\% \\
2.93\end{array}$ & $\begin{array}{l}\% \\
0.83 \\
0.70\end{array}$ & $\begin{array}{l}\% \\
0.31\end{array}$ \\
\hline 12 & $\begin{array}{l}\text { Chylomicron } \\
\text { Oil }\end{array}$ & $\begin{array}{l}96.2 \\
99.6\end{array}$ & 3.23 & $\begin{array}{l}0.52 \\
0.29\end{array}$ & \\
\hline 9 & $\begin{array}{l}\text { Chylomicron } \\
\text { Oil } \\
\text { Membrane } 1 \S \\
\text { Membrane } 2\end{array}$ & $\begin{array}{l}94.7 \\
99.3 \\
22.6 \\
25.2\end{array}$ & $\begin{array}{c}4.30 \\
70.2 \\
67.9\end{array}$ & $\begin{array}{l}0.83 \\
0.51 \\
7.30 \\
6.89\end{array}$ & $\begin{array}{l}0.60 \\
\\
4.41 \\
0.42\end{array}$ \\
\hline 11 & $\begin{array}{l}\text { Chylomicron } \\
\text { Oil } \\
\text { Membrane }\end{array}$ & $\begin{array}{l}96.9 \\
99.6 \\
12.8\end{array}$ & $\begin{array}{r}2.37 \\
76.7\end{array}$ & $\begin{array}{l}0.73 \\
0.37 \\
10.4\end{array}$ & $\begin{array}{l}0.73 \\
11.8\end{array}$ \\
\hline 19 & $\begin{array}{l}\text { Chylomicron } \\
\text { Oil } \\
\text { Membrane }\end{array}$ & $\begin{array}{l}97.0 \\
99.3 \\
16.4\end{array}$ & $\begin{array}{c}4.10 \\
0.12 \\
76.1\end{array}$ & $\begin{array}{l}0.85 \\
0.43 \\
7.70\end{array}$ & $\begin{array}{l}0.31 \\
2.14\end{array}$ \\
\hline 24 & $\begin{array}{l}\text { Chylomicron } \\
\text { Oil } \\
\text { Membrane }\end{array}$ & $\begin{array}{l}95.4 \\
99.3 \\
16.1\end{array}$ & $\begin{array}{c}3.51 \\
75.3\end{array}$ & $\begin{array}{l}0.88 \\
0.49 \\
8.67\end{array}$ & $\begin{array}{l}0.57 \\
3.11\end{array}$ \\
\hline 16 & Membrane & 22.8 & 72.3 & 4.85 & \\
\hline
\end{tabular}

* All dogs were fed corn oil.

$\dagger$ Percentages of total lipid. Total lipid in Tables II and III was calculated as the sum of triglyceride, phospholipid $P \times 25$, free cholesterol, esterified cholesterol $\times 1.7$.

$\ddagger$ Percentages of total weight.

$\$$ Membrane 1 was harvested after 20 minutes centrifugation at $100,000 \mathrm{~g}$, membrane 2 after centrifuging the supernatant from the first centrifugation 24 hours.

position of intact lymph chylomicrons, oil phase, and membrane from dogs fed corn oil. On the average the weight of the membrane fraction was about $5 \%$ of the total chylomicron weight; the rest was oil. In each instance the oil phase was found to contain an appreciable amount of cholesterol but practically no phospholipid. In the few instances in which a measurable amount of phospholipid was found to be present in the oil phase, this may have been due to contamination of the oil with adhering intact chylomicrons or membrane fragments. The cholesterol found in the oil phase consisted of both free and esterified cholesterol (Table IV) in contrast to that present in the membrane, which was present entirely in the free form.

The main component of the membrane fraction was found to be phospholipid. In most instances 70 to $75 \%$ of the total membrane lipid was present in that form with smaller amounts of triglyceride (13 to $25 \%$ ) and free cholesterol (5 to $10 \%$ ) making up the rest of the lipid. The absence of appreciable amounts of cholesterol ester from the membrane fraction was demonstrated not only qualitatively by thin layer chromatography but in several instances also by quantitative analysis of the appropriate silicic acid column eluate. In no instance did the esterified cholesterol comprise more than $0.5 \%$ of the total membrane cholesterol. In two instances (dogs 19 and 24) a special attempt was made to separate and recover the oil and membrane fractions quantitatively. These analyses, which agreed closely with one another, demonstrate that the membrane contains all of the phospholipid, about $70 \%$ of the free cholesterol, less than $1 \%$ of the triglyceride, and essentially none of the cholesterol ester of the intact chylomicron.

Kjeldahl analyses of two different alcohol-ether extracted membrane fractions showed a 15 to $16 \%$ nitrogen content. On this basis washed chylomicrons had a protein content of 0.3 to $0.7 \%$. It has been reported that the protein of human chylomicrons can be lowered drastically by additional washing (15). This has not been our experience with dog lymph chylomicrons. This type of experiment is, however, difficult to interpret, since progressive oiling out of chylomicrons during the washing procedure lowers the total surface to volume ratio of the fat particles, which may greatly affect the percentage of protein (4).

The membrane fraction showed a relatively 

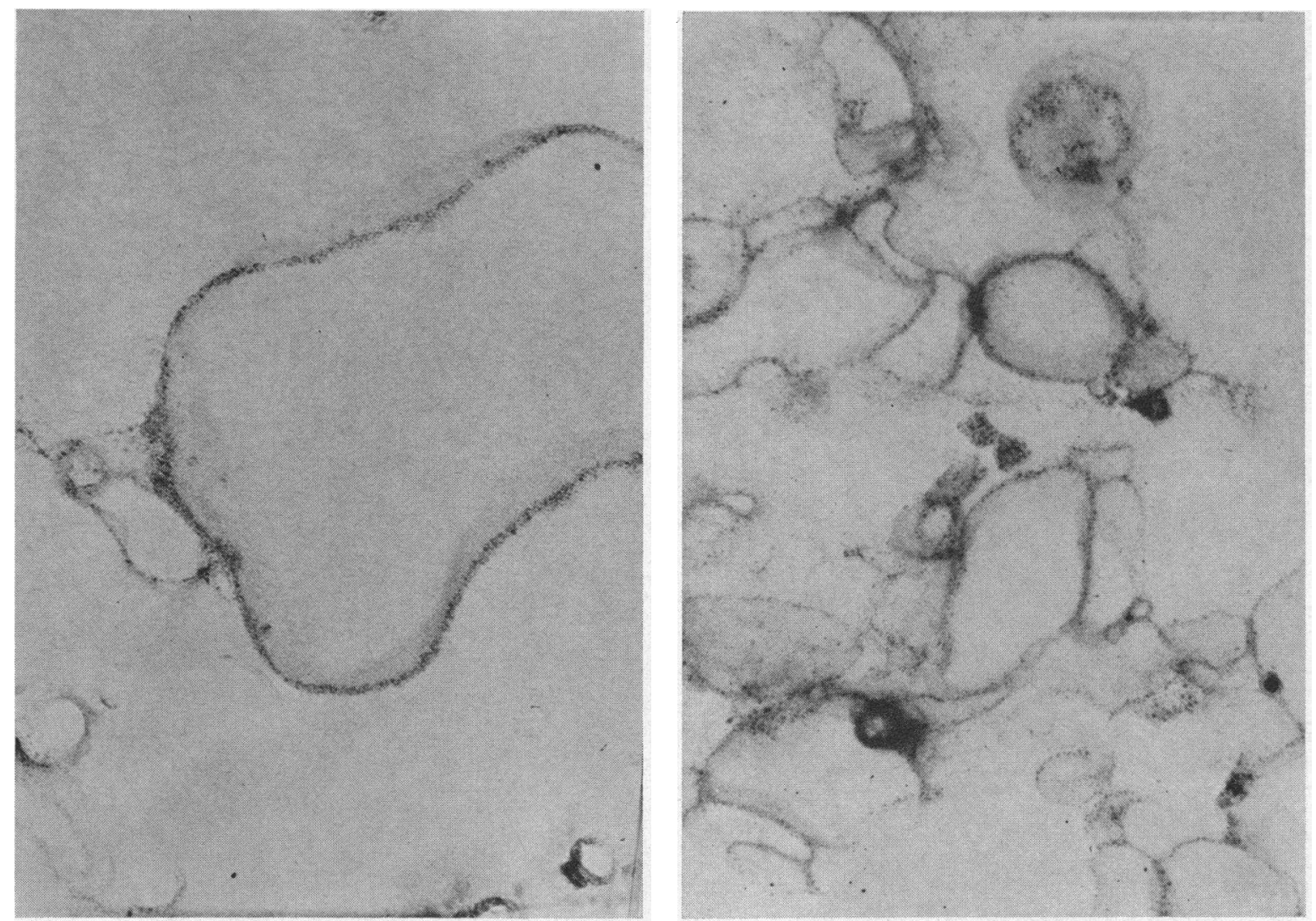

Fig. 1. Chylomicron membrane fractions ( $\times 100,000)$. Left: sedimented for 20 minutes at $100,000 \mathrm{~g}$. Right: sedimented after an additional 24 hours at $100,000 \mathrm{~g}$.

much higher percentage of protein than the whole chylomicron, which is to be expected. It was surprising, however, that the percentage of protein differed so much from sample to sample. Even within the same preparation two membrane fractions ( $\operatorname{dog} 9$, Table II) differed in protein content by a factor of ten. The membrane fraction, which was centrifuged down in 20 minutes at 100,$000 \mathrm{~g}$, had a protein content of about $4 \%$. The membrane fraction isolated after an additional centrifugation at 24 hours showed only one-tenth as much protein per gram dry weight. According to the electron microscopic study, the 24-hour fraction showed the presence of smaller fragments (Figure 1, upper and lower). Since phospholipid and protein are found in the membrane fraction but not in the oil phase, it is of interest to note that the protein to phospholipid ratio is considerably lower in the isolated membrane than in the intact chylomicron. As practically all the phospholipid was recovered in the membrane pellet, soluble protein must have been lost during the disintegration of the chylomicron and subsequent washing of the membrane fraction. The loss relative to phospholipid may have been greater in the smaller fragments ( $\operatorname{dog} 9$, membrane 2 ) than in the larger ones $(\operatorname{dog} 9$, membrane 1$)$. Apart from the ring of electron dense material in Figure 1, no fibrillar structures are seen in the center. This represents direct evidence for the view, expressed previously on the basis of chemical data (4), that the protein and polar lipids are situated only on the surface of the chylomicron.

In Table III triglyceride, phospholipid, and cholesterol contents of chylomicrons from a patient and three rats are shown. In each instance the cream chylomicrons contained slightly more phospholipid and cholesterol than the corn oil chylomicrons, but more analyses are needed tó judge the significance of these differences. Membrane fractions showed compositions similar to those shown for the dog in Table II. However, the cholesterol to phospholipid ratios of the rat chylomicron and membrane fractions were much lower 
LYMPH CHYLOMICRONS

TABLE III

Lipids in human and rat lymph chylomicrons*

\begin{tabular}{|c|c|c|c|c|c|c|c|}
\hline \multirow[b]{2}{*}{ Species } & \multirow[b]{2}{*}{ Fraction } & \multicolumn{2}{|c|}{ Triglyceride } & \multicolumn{2}{|c|}{ Phospholipid } & \multicolumn{2}{|c|}{ Cholesterol } \\
\hline & & Corn oil & Cream & Corn oil & Cream & Corn oil & Cream \\
\hline & & \multicolumn{2}{|c|}{$\%$} & \multicolumn{2}{|c|}{$\%$} & \multicolumn{2}{|c|}{$\%$} \\
\hline Humant & $\begin{array}{l}\text { Chylomicron } \\
\text { Membrane }\end{array}$ & $\begin{array}{l}96.5 \\
43.0\end{array}$ & $\stackrel{94.3}{\ddagger}$ & $\begin{array}{l}2.85 \\
52.8\end{array}$ & $\stackrel{4.36}{\ddagger}$ & $\begin{array}{l}0.61 \\
4.78\end{array}$ & 0.73 \\
\hline Rat§ & $\begin{array}{l}\text { Chylomicron } \\
\text { Membrane }\end{array}$ & $\begin{array}{l}95.1 \\
10.5\end{array}$ & $\begin{array}{l}94.3 \\
32.7\end{array}$ & $\begin{array}{l}4.55 \\
86.5\end{array}$ & $\begin{array}{l}5.05 \\
66.3\end{array}$ & $\begin{array}{l}0.31 \\
3.01\end{array}$ & $\begin{array}{l}0.54 \\
1.03\end{array}$ \\
\hline Rat $†$ & $\begin{array}{l}\text { Chylomicron } \\
\text { Membrane }\end{array}$ & $\begin{array}{l}96.0 \\
21.0\end{array}$ & $\begin{array}{l}93.0 \\
22.5\end{array}$ & $\begin{array}{l}3.65 \\
76.0\end{array}$ & $\begin{array}{c}6.32 \\
76.0\end{array}$ & $\begin{array}{l}0.32 \\
2.89\end{array}$ & $\begin{array}{l}0.57 \\
1.40\end{array}$ \\
\hline
\end{tabular}

* Percentages of total lipid. Protein content of human cream chylomicrons $=0.15 \%$, corn oil chylomicrons $=$ $0.58 \%$, and corn oil chylomicron membrane $=11.5 \%$ of total weight.

t One patient and one rat each received both corn oil and cream.

Insufficient membrane for analysis.

$\$$ One rat received corn oil and one received cream.

than in the dog or in man. In the membranes from rats the ratios varied between 0.02 and 0.04 , whereas in dog and man they were close to 0.10 . Again, all the cholesterol of membrane was unesterified.

The absence of esterified cholesterol from the chylomicron membrane raised the question of whether the oil phase of the chylomicrons contains both esterified and unesterified cholesterol. Data on this point are presented in Table IV. In each instance the percentage of cholesterol present as ester in the oil phase was higher than that in the whole chylomicron from which the oil was derived, but appreciable amounts of free cholesterol were also present in the oil phase.

Since other workers had reported that after feeding cholesterol the thoracic duct lymph of rats contains cholesterol primarily in the esterified form, it was of interest to determine the percentage of cholesterol ester in chylomicron-free lymph from animals fed corn oil or cream. Table IV shows that, irrespective of the diet, in each instance the cholesterol in the lymph subnatant was more completely esterified than that in the corresponding chylomicron fraction. In the case of the patient fed cream and corn oil, whole lymph was

TABLE IV

Esterified cholesterol in lymph chylomicrons and subnatant

\begin{tabular}{|c|c|c|c|c|c|}
\hline \multirow[b]{2}{*}{ Species } & \multirow[b]{2}{*}{ No. } & \multirow[b]{2}{*}{ Diet } & \multicolumn{3}{|c|}{ Esterified cholesterol* } \\
\hline & & & $\begin{array}{l}\text { Whole } \\
\text { chylomicron }\end{array}$ & $\underset{\text { oil }}{\text { Chylomicron }}$ & $\underset{\text { subnatant }}{\text { Lymph }}$ \\
\hline Dog & $\begin{array}{r}9 \\
10 \\
19 \\
12 \\
24\end{array}$ & $\begin{array}{l}\text { Corn oil } \\
\text { Corn oil } \\
\text { Corn oil } \\
\text { Corn oil } \\
\text { Corn oil }\end{array}$ & $\begin{array}{l}\% \\
24.6 \\
42.9 \\
24.8 \\
17.0 \\
33.0\end{array}$ & $\begin{array}{c}\% \\
46.2 \\
\dagger \\
\dagger \\
29.1 \\
60.2\end{array}$ & $\begin{array}{c}\% \\
t \\
t \\
t \\
65.7 \\
t\end{array}$ \\
\hline Rat & $\begin{array}{l}2 \\
3 \\
1 \\
2\end{array}$ & $\begin{array}{l}\text { Corn oil } \\
\text { Corn oil } \\
\text { Cream } \\
\text { Cream }\end{array}$ & $\begin{array}{l}23.0 \\
22.6 \\
45.4 \\
41.9\end{array}$ & $\begin{array}{l}33.0 \\
32.1 \\
58.8 \\
52.7\end{array}$ & $\begin{array}{l}67.8 \\
55.3 \\
63.8 \\
57.0\end{array}$ \\
\hline Human $\ddagger$ & & $\begin{array}{l}\text { Corn oil } \\
\text { Cream }\end{array}$ & $\begin{array}{l}16.1 \\
32.4\end{array}$ & $\begin{array}{l}37.4 \\
53.6\end{array}$ & $\begin{array}{l}78.8 \\
78.0\end{array}$ \\
\hline
\end{tabular}

* Percent of total cholesterol in each fraction.

$\dagger$ Not determined.

$\ddagger$ In whole lymph the percentage of esterified cholesterol was $53.3 \%$ after cream and $56.4 \%$ after corn oil feeding After cream feeding $48 \%$ of the total lymph cholesterol was present in the chylomicrons, whereas after corn oil only $25 \%$ was present in that fraction. 
D. B. ZILVERSMIT

TABLE V

Chylomicron triglyceride fatty acids

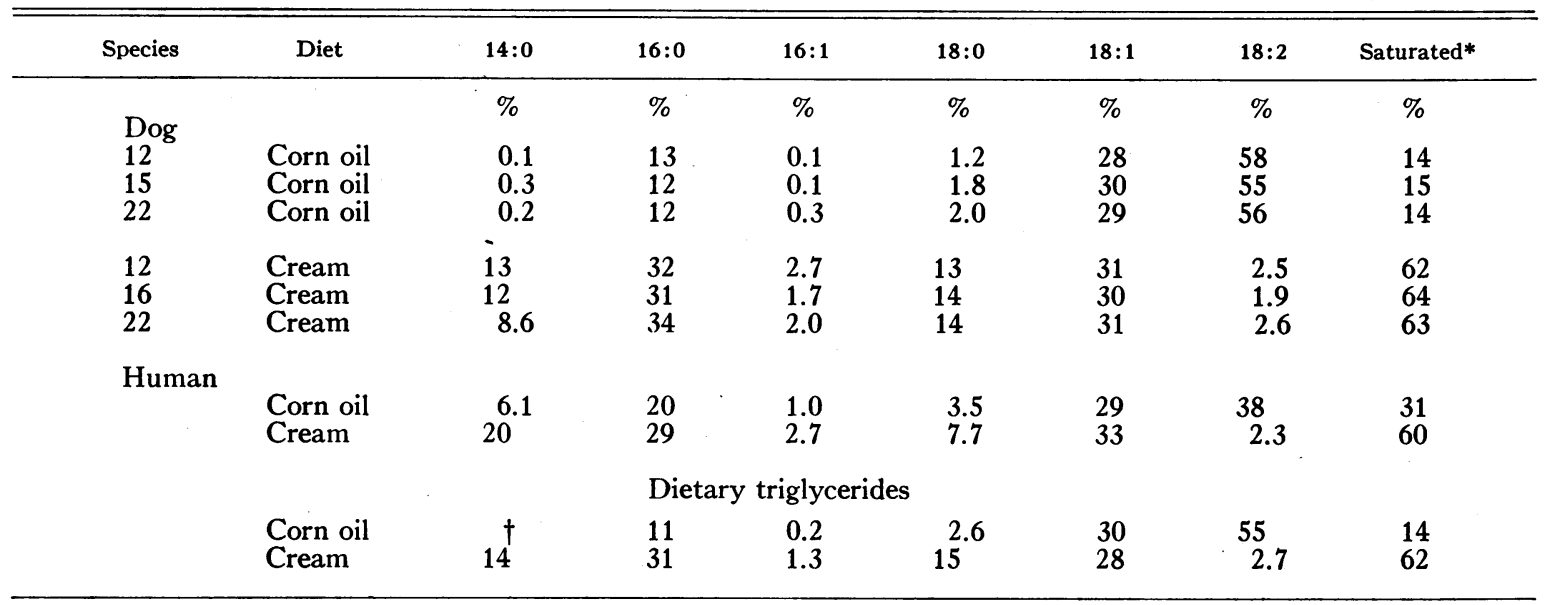

* Any single peak omitted is less than $4 \%$. The total excludes no more than $9 \%$.

$\dagger$ Less than $0.1 \%$.

also analyzed for various lipid fractions. In both instances the esterified cholesterol represented about $55 \%$ of the total lymph cholesterol.

Gas-liquid chromatography. In Table $\mathrm{V}$ the composition of chylomicron triglyceride in one patient and four dogs is compared with the fatty acid composition of the diet. As was to be expected, the chylomicron triglyceride fatty acids mirrored the composition of the dietary fat. Notable differences between cream and corn oil chylomicrons are the presence of shorter chain fatty acids, primarily $\mathrm{C} 14: 0$, in the former and a predominance of $18: 2$ acids in the latter. In the dogs the correspondence between fatty acid composition of chylomicron triglyceride and dietary fat was closer than that observed by Nestel and Scow
(16). This may be due to the higher fat loads used in our experiments. In the patient, who received cream about 24 hours before the corn oil, the relatively high myristic acid content and somewhat low linoleate content of the chylomicrons after corn oil feeding indicated a possible retention of cream lipids after the corn oil had been administered. A similar overlap of fatty acid composition was observed by Kayden, Karmen, and Dumont (6).

Fatty acid analyses on cholesterol esters eluted from silicic acid columns and subsequently subjected to thin layer chromatography were attempted. However, replicate analyses in some instances showed widely divergent values, and the results are, therefore, not reported here.

TABLE VI

Chylomicron total phospholipid fatty acids

\begin{tabular}{ccccccccc}
\hline \hline Species & Diet & $14: 0$ & $16: 0$ & $18: 0$ & $18: 1$ & $18: 2$ & $20: 4$ & Saturated* \\
\hline Dog & & $\%$ & $\%$ & $\%$ & $\%$ & $\%$ & $\%$ & $\%$ \\
11 & Corn oil & $\dagger$ & 18 & 25 & 12 & 39 & 6.5 & 43 \\
12 & Corn oil & $\dagger$ & 18 & 20 & 12 & 42 & 3.7 & 42 \\
12 & Cream & 2.5 & 30 & 25 & 15 & 21 & 6.1 & 58 \\
Y & Cream & 3.4 & 22 & 29 & 16 & 21 & 8.5 & 55 \\
16 & Cream & 1.5 & 22 & 26 & 17 & 19 & 8.6 & 51 \\
Human & & & & & & & & \\
& Corn oil & 1.0 & 29 & 15 & 21 & 30 & 2.3 & 45 \\
& Cream & 0.8 & 35 & 16 & 14 & 23 & 6.7 & 53 \\
\hline
\end{tabular}

* Any single peak omitted is less than $4 \%$. The total excludes no more than $6 \%$.

$\dagger$ No peaks detected. 
TABLE VII

Chylomicron individual phospholipid fatty acids

\begin{tabular}{|c|c|c|c|c|c|c|c|c|}
\hline Species & Diet & Phospholipid* & $16: 0$ & $18: 0$ & $18: 1$ & $18: 2$ & $20: 4$ & Saturated $\dagger$ \\
\hline Dog & & & $\%$ & $\%$ & $\%$ & $\%$ & $\%$ & $\%$ \\
\hline $\begin{array}{l}11 \\
12 \\
22 \\
12 \\
22\end{array}$ & $\begin{array}{l}\text { Corn oil } \\
\text { Corn oil } \\
\text { Corn oil } \\
\text { Cream } \\
\text { Cream }\end{array}$ & $\begin{array}{l}\text { PE } \\
\text { PE } \\
\text { PE } \\
\text { PE } \\
\text { PE }\end{array}$ & $\begin{array}{c}7.5 \\
6.1 \\
6.4 \\
6.2 \\
12\end{array}$ & $\begin{array}{l}26 \\
38 \\
45 \\
42 \\
46\end{array}$ & $\begin{array}{l}18 \\
14 \\
13 \\
17 \\
11\end{array}$ & $\begin{array}{c}35 \\
29 \\
27 \\
20 \\
7.8\end{array}$ & $\begin{array}{c}11 \\
6.9 \\
3.6 \\
15 \\
8.4\end{array}$ & $\begin{array}{l}34 \\
49 \\
54 \\
48 \\
61\end{array}$ \\
\hline $\begin{array}{l}11 \\
12 \\
22 \\
12 \\
22\end{array}$ & $\begin{array}{l}\text { Corn oil } \\
\text { Corn oil } \\
\text { Corn oil } \\
\text { Cream } \\
\text { Cream }\end{array}$ & $\begin{array}{l}\text { PC } \\
\text { PC } \\
\text { PC } \\
\text { PC } \\
\text { PC }\end{array}$ & $\begin{array}{l}20 \\
19 \\
22 \\
28 \\
24\end{array}$ & $\begin{array}{l}23 \\
22 \\
23 \\
34 \\
29\end{array}$ & $\begin{array}{l}15 \\
11 \\
10 \\
14 \\
14\end{array}$ & $\begin{array}{l}36 \\
43 \\
40 \\
20 \\
20\end{array}$ & $\begin{array}{c}4.4 \\
4.7 \\
4.5 \\
3.5 \\
10\end{array}$ & $\begin{array}{l}45 \\
41 \\
45 \\
63 \\
54\end{array}$ \\
\hline $\begin{array}{l}22 \\
28 \\
29 \\
22 \\
28 \\
29\end{array}$ & $\begin{array}{l}\text { Corn oil } \\
\text { Corn oil } \\
\text { Corn oil } \\
\text { Cream } \\
\text { Cream } \\
\text { Cream }\end{array}$ & $\begin{array}{l}\text { Sphingo } \\
\text { Sphingo } \\
\text { Sphingo } \\
\text { Sphingo } \\
\text { Sphingo } \\
\text { Sphingo }\end{array}$ & $\begin{array}{r}60 \\
88 \\
68 \\
45 \\
56 \\
71\end{array}$ & $\begin{array}{c}25 \\
7.5 \\
28 \\
29 \\
35 \\
24\end{array}$ & $\begin{array}{l}4.3 \\
t \\
t \\
6.3 \\
t \\
t\end{array}$ & $\begin{array}{l}7.9 \\
0.2 \\
\ddagger \\
4.3 \\
\ddagger \\
\ddagger\end{array}$ & $\begin{array}{l}2.3 \\
0.2 \\
\ddagger \\
4.1 \\
\ddagger \\
\ddagger\end{array}$ & $\begin{array}{l}86 \\
99 \\
99 \\
81 \\
95 \\
97\end{array}$ \\
\hline $\begin{array}{l}11 \\
12 \\
22 \\
12 \\
22\end{array}$ & $\begin{array}{l}\text { Corn oil } \\
\text { Corn oil } \\
\text { Corn oil } \\
\text { Cream } \\
\text { Cream }\end{array}$ & $\begin{array}{l}\text { Lyso } \\
\text { Lyso } \\
\text { Lyso } \\
\text { Lyso } \\
\text { Lyso }\end{array}$ & $\begin{array}{l}51 \\
60 \\
18 \\
31 \\
28\end{array}$ & $\begin{array}{l}35 \\
33 \\
62 \\
46 \\
39\end{array}$ & $\begin{array}{l}5.0 \\
0.7 \\
7.9 \\
9.6 \\
8.5\end{array}$ & $\begin{array}{l}9.0 \\
3.6 \\
4.4 \\
13 \\
20\end{array}$ & $\begin{array}{l}\ddagger \\
\ddagger \\
2.5 \\
\ddagger \\
2.9\end{array}$ & $\begin{array}{l}86 \\
94 \\
82 \\
77 \\
68\end{array}$ \\
\hline
\end{tabular}

* $\mathrm{PE}=$ phosphatidyl ethanolamine, $\mathrm{PC}=$ phosphatidyl choline, sphingo = sphingomyelin, and lyso $=$ lysolecithin $\dagger$ Any single peak omitted is less than 5\%. The total excludes no more than $10 \%$ except for dog $22 \mathrm{cream} P E$, which excludes $15 \%$.

$\ddagger$ No peaks detected.

Phospholipid fatty acids are shown in Table VI. The composition of these lipids is rather independent of dietary fat; neither 16:0 nor 18:0 appears to differ significantly in cream and corn oil chylomicrons, but the $18: 2$ in the oil-fed dogs is nearly twice that of the dogs fed cream. In the human a similar difference, although less pronounced, is evident. Since the phospholipids make up such a large portion of the chylomicron membrane and since their composition may be intimately related to the stability of the membrane, a further study of the individual phospholipid fractions of chylomicrons from three dogs was undertaken. Phosphorus analyses on silicic acid column eluates (17) showed no differences in the relative mole percentages of phosphatidyl ethanolamine $(12 \%)$, phosphatidyl choline $(75 \%)$, sphingomyelin $(5 \%)$, and lysolecithin $(3 \%)$ in the chylomicrons from cream and corn oil fed animals. This distribution agrees well with the distribution of phospholipids found previously (8) and differs from that in dog serum, which contains relatively less phosphatidyl ethanolamine and more sphingomyelin and lysolecithin (8). Table VII presents the gas liquid chromatography analyses of individual phospholipid fractions. Little, if any, fatty acids shorter than 16 carbons were found in any of the phospholipid fractions. On the other end of the spectrum the various phospholipid fractions contained appreciable amounts of $20: 4$, which was not present to any significant extent in the dietary fat. As a group the phospholipid fatty acids were not greatly affected by changes in dietary fat, although it would appear that the phosphatidyl choline of corn oil chylomicrons was richer in 18:2 than that of cream chylomicrons. About half of the fatty acids of phosphatidyl ethanolamine and phosphatidyl choline were saturated. In four of six sphingomyelin fractions the degree of saturation was $95 \%$ or greater with palmitic acid by far the largest component. Fatty acids of chain length greater than 18 were practically absent in the sphingomyelin of corn oil chylomicrons and were present only in small amounts of cream chylomicrons. In the latter, small quantities $(<5 \%)$ of $20: 4,22: 5$, and $24: 1$ were found as well as traces of $20,22,23$, and 24 saturates. It was of interest to compare the fatty 
TABLE VIII

Sphingomyelin fatty acids of plasma and brain

\begin{tabular}{cccccccccc}
\hline \hline & $16: 0$ & $18: 0$ & $20: 0$ & $22: 0$ & $23: 0$ & $24: 0$ & $24: 1$ & $>24: 1$ & Saturated* \\
\hline Dog & $\%$ & $\%$ & $\%$ & $\%$ & $\%$ & $\%$ & $\%$ & $\%$ & $\%$ \\
$28 \dagger$ & 46 & 28 & 4.2 & 6.3 & 5.9 & 5.4 & 3.2 & $\ddagger$ & 97 \\
$28 \S$ & 50 & 27 & 2.8 & 3.6 & 2.9 & 2.6 & 5.7 & $\ddagger$ & 92 \\
$29 \S$ & 46 & 22 & 3.4 & 4.2 & 5.7 & 5.3 & 2.0 & $\ddagger$ & 94 \\
Beef & 3.2 & 53 & 0.8 & 4.4 & 3.9 & 14 & 11 & 8.9 & 83 \\
$\quad$ brain & & & & & & & & & \\
\hline
\end{tabular}

* Any single peak omitted is less than $4 \%$. The total excludes no more than $11 \%$.

t Intact animal, postabsorptive blood specimen.

$\ddagger$ No peaks detected.

$\S$ Thoracic duct cannulated, blood specimen during absorption of corn oil.

acid composition of dog plasma sphingomyelin to that of the chylomicrons. In two dogs clear plasma was obtained at the time of lymph collection. In one of them postabsorptive plasma had previously been analyzed. These analyses and that of a commercial sample ${ }^{5}$ of beef brain sphingomyelin are given in Table VIII. It is apparent that 20 to $25 \%$ of the fatty acids from dogs serum sphingomyelin contains more than 18 carbons. Although this percentage is high compared to that of dog chylomicrons, it is not nearly so high as the $43 \%$ for beef brain sphingomyelin (Table VIII) or the approximately $45 \%$ reported for sphingomyelin from plasma chylomicrons in butter-fed patients (18) or from fasting human plasma (19). The most striking difference in fatty acid composition of beef brain sphingomyelin and the others is the low percentage of 16:0 in the former.

5 Applied Science, State College, Pa.
The only other fatty acid-containing portion of the chylomicron membrane is the triglyceride fraction. It seemed important, therefore, to isolate these triglycerides and subject them to gas liquid chromatography analysis. Initially, the membrane triglyceride was thought to represent a contamination of the membrane pellet with unbroken adhering chylomicrons. This idea was discarded, however, when gas liquid chromatography analyses showed large differences in the fatty acid composition of whole chylomicron triglyceride and the triglyceride of chylomicron membrane. A detailed study of chylomicron membrane and oil fractions in one patient, three dogs, and two rats is presented in Table IX. The last two columns of this Table show that the membrane triglycerides, particularly after feeding corn oil, contain a much higher proportion of saturated fatty acids than the triglycerides that constitute the major lipid

TABLE IX

Triglyceride fatty acids in chylomicron oil and membrane

\begin{tabular}{|c|c|c|c|c|c|c|c|c|c|c|c|c|c|}
\hline \multirow[b]{2}{*}{ Species } & \multirow[b]{2}{*}{ Diet } & \multicolumn{2}{|c|}{$14: 0$} & \multicolumn{2}{|c|}{$16: 0$} & \multicolumn{2}{|c|}{$18: 0$} & \multicolumn{2}{|c|}{$18: 1$} & \multicolumn{2}{|c|}{$18: 2$} & \multicolumn{2}{|c|}{ Saturated $\dagger$} \\
\hline & & $0 *$ & $\mathbf{M}^{*}$ & 0 & $\mathbf{M}$ & 0 & $\mathbf{M}$ & 0 & $\mathbf{M}$ & 0 & $\mathbf{M}$ & $\overline{0}$ & $\mathbf{M}$ \\
\hline Dog & & \multicolumn{2}{|c|}{$\%$} & \multicolumn{2}{|c|}{$\%$} & \multicolumn{2}{|c|}{$\%$} & \multicolumn{2}{|c|}{$\%$} & \multicolumn{2}{|c|}{$\%$} & \multicolumn{2}{|c|}{$\%$} \\
\hline $\begin{array}{l}11 \\
15 \\
16\end{array}$ & $\begin{array}{l}\text { Oil } \\
\text { Oil } \\
\text { Cream }\end{array}$ & $\begin{array}{l}0.1 \\
0.3 \\
12\end{array}$ & $\begin{array}{l}1.8 \\
1.4 \\
13\end{array}$ & $\begin{array}{l}12 \\
12 \\
31\end{array}$ & $\begin{array}{l}44 \\
49 \\
39\end{array}$ & $\begin{array}{l}1.7 \\
2.0 \\
14\end{array}$ & $\begin{array}{c}11 \\
8.2 \\
19\end{array}$ & $\begin{array}{l}29 \\
29 \\
30\end{array}$ & $\begin{array}{l}17 \\
15 \\
22\end{array}$ & $\begin{array}{l}56 \\
53 \\
1.9\end{array}$ & $\begin{array}{r}25 \\
22 \\
\ddagger\end{array}$ & $\begin{array}{l}14 \\
14 \\
64\end{array}$ & $\begin{array}{l}58 \\
59 \\
77\end{array}$ \\
\hline \multicolumn{14}{|c|}{ Human } \\
\hline & Oil & 3.2 & 9.0 & 16 & 58 & 3.6 & 13 & 29 & 9.8 & 40 & 5.5 & 27 & 84 \\
\hline \multicolumn{14}{|l|}{ Rat } \\
\hline $\begin{array}{l}2 \\
3\end{array}$ & $\begin{array}{l}\text { Oil } \\
\text { Oil }\end{array}$ & $\begin{array}{l}0.2 \\
0.6\end{array}$ & $\begin{array}{l}1.0 \\
0.4\end{array}$ & $12^{9.5}$ & $\begin{array}{l}32 \\
47\end{array}$ & $\begin{array}{l}1.3 \\
1.6\end{array}$ & $\begin{array}{l}5.1 \\
6.9\end{array}$ & $\begin{array}{l}28 \\
31\end{array}$ & $\begin{array}{l}21 \\
19\end{array}$ & $\begin{array}{l}60 \\
53\end{array}$ & $\begin{array}{l}39 \\
25\end{array}$ & $\begin{array}{l}11 \\
15\end{array}$ & $\begin{array}{l}38 \\
55\end{array}$ \\
\hline
\end{tabular}

* $O$, oil phase of chylomicron except $\operatorname{dog} 16$, which is whole chylomicron; $M$, membrane of chylomicron. $\dagger$ Any single peak omitted is less than $3 \%$. The total excludes no more than $11 \%$.

$\ddagger$ No peaks detected. 
fraction of the chylomicron oil phase. Possibly the difference in the degree of saturation between triglycerides of membrane and oil phase resulted from the selective accumulation of saturated triglycerides in the membrane phase during freezing. Preliminary data on chylomicron membrane and oil prepared without cooling below $25^{\circ} \mathrm{C}$ showed considerably smaller differences in the degree of saturation than those in Table IX.

\section{Discussion}

Preliminary reports from this laboratory stated that corn oil chylomicrons oil out more easily when subjected to freezing than do cream chylomicrons $(20,21)$, and this study was undertaken to elucidate, among other things, this difference in stability. When detailed chemical examination of the two types of chylomicrons failed to reveal any major differences in composition except for the fatty acid composition of the triglyceride fractions, the original observations on relative stability were repeated. The earlier freezing experiments were carried out at $-40^{\circ} \mathrm{C}$ with subsequent reheating to room temperature or to $40^{\circ} \mathrm{C}$. Since butter is largely liquid at temperatures above $32^{\circ} \mathrm{C}$, it was assumed that cream chylomicron triglyceride would be liquid at $40^{\circ} \mathrm{C}$. However, when sufficient cream chylomicron triglyceride was available to perform a melting point determination, it became evident that this triglyceride did not begin to flow until 41 to $42^{\circ} \mathrm{C}$. Apparently the loss from cream of short chain fatty acids, which are absorbed by the portal vein, produces chylomicrons that are semisolid at body temperature. In later experiments ${ }^{6}$ washed cream and corn oil chylomicrons were frozen and reheated to $60^{\circ} \mathrm{C}$. By this procedure considerable oiling out was achieved for both cream and corn oil chylomicrons. It then became of interest to find out whether solidification of the fat without freezing the water might suffice to cause oiling out. This was shown to be the case for cream chylomicrons cooled to $4^{\circ} \mathrm{C}$ and reheated to $60^{\circ} \mathrm{C}$, a procedure that failed to liberate oil from corn oil chylomicrons but liberated 25 to $35 \%$ of the cream chylomicron triglyceride as oil. Subsequent work showed that lyophilization of washed cream or corn oil chylomicrons followed by heating to $60^{\circ} \mathrm{C}$ for cream chylomicrons

\footnotetext{
${ }^{6}$ After completion of the analytical studies presented in the Results section.
}

and to room temperature for corn oil chylomicrons provided an efficient oiling-out procedure.

The foregoing considerations are pertinent to the interpretation of studies concerned with chylomicron metabolism. Cream chylomicrons collected, washed, or stored in the cold quite likely contain many particles with ruptured membranes. The observation that washed cream chylomicrons disappear from the circulation more rapidly than corn oil chylomicrons (16) may, in part, be due to the greater proportion of disrupted particles in the former preparation. Whether disruption of chylomicrons in native chyle takes place as readily is not known, but we have been able to liberate oil by freezing lymph from dogs fed corn oil.

Previous studies (5) showed that when human serum lipoproteins were spread in a thin film between heptane and water, all the free and esterified cholesterol dissolved in the heptane phase. The membrane of a chylomicron may be considered as a lipoprotein spread between an oil and aqueous phase. It is interesting, therefore, that although all the cholesterol ester of the chylomicron appeared to be present in the oil phase, most of the free cholesterol was present in the membrane. One might explain this by postulating a strong bond between free cholesterol and some other chylomicron membrane constituent. This is, however, not likely, since chylomicron free cholesterol exchanges readily with cholesterol in serum lipoproteins (22). A more likely explanation is the lower solubility of free cholesterol in triglyceride than in heptane. On the basis of this explanation one would predict that free cholesterol would favor the chylomicron surface more in corn oil than in cream chylomicrons, since it has been shown that cholesterol is more soluble in saturated than in unsaturated fat $(23,24)$.

The structure of a chylomicron membrane is difficult to ascertain at present. The appearance of ghost-like rings in the electron micrographs suggests a certain structural rigidity of the isolated membrane. What binding forces are responsible for such rigidity in a material that consists primarily of lipid is not clear although an analogous situation may be found in myelin figures (25). Electron micrographs have not revealed the presence of a unit membrane such as is found in a variety of cells. One would, however, not expect a unit membrane in this instance, since in 
the intact chylomicron one side of the membrane is exposed to a polar medium and the other side to oil. If we assume an average chylomicron diameter of $0.3 \mu(26,27)$ with a density of 0.94 (26), we find that a $4 \%$ phospholipid content would suffice to form a monomolecular surface layer allowing $70 \mathrm{~A}^{2}$ per molecule. This would correspond to a film pressure of about 20 dynes per $\mathrm{cm}$ if the phospholipid were phosphatidyl choline with one stearic and one oleic acid (28). If the $0.5 \%$ of chylomicron protein occupied the entire surface of $0.3-\mu$ particles, $1 \mathrm{mg}$ of protein would be spread over $5 \mathrm{~m}^{2}$. At an oil-water interface and 20 dynes per $\mathrm{cm}$ film pressure, a film of $1 \mathrm{mg}$ protein would occupy only about $0.5 \mathrm{~m}^{2}(29,30)$. If, therefore, the chylomicron protein were interspersed with phospholipid at a film pressure of 20 dynes per $\mathrm{cm}$, the protein would occupy only about $10 \%$ of the chylomicron surface. Both cholesterol and triglyceride are known to form with phospholipids mixed films that are more compact than films of pure phospholipid $(28,31)$. It is not unlikely, therefore, that on the chylomicron surface small quantities of saturated triglyceride, free cholesterol, and protein form a mosaic in a film composed primarily of phospholipid.

To compare some of our results with those reported in other laboratories, one should differentiate between lymph and plasma chylomicrons, since gross changes in phospholipid and free cholesterol content have been shown to take place when lymph chylomicrons are incubated with plasma (8). One other point that has led to some confusion is that some investigators have reported the lipid composition of whole lymph and others that of isolated washed chylomicrons. The data reported in Table IV show, for example, that the chylomicronfree lymph subnatant contains a much higher percentage of esterified cholesterol than the chylomicrons. Vahouny, Fawal, and Treadwell reported for whole rat lymph that about $75 \%$ of the cholesterol is in the esterified form $(32,33)$. Swell and his colleagues reported an average of $86 \%$ of cholesterol in the ester form (34). Values of $65 \%$ were reported by Daskalakis and Chaikoff (35). Chevallier and Vyas reported values of $50 \%$ (36). On isolated rat chylomicrons Savary, Constantin, and Desnuelle reported esterified cholesterol as $50 \%$ when triglyceride was fed and $68 \%$ when fatty acid was fed (37).
Similar conclusions were reached by Woo and Treadwell (38). In patients with chyluria Peters and Man reported $75 \%$ of the chylomicron cholesterol in the ester form (39), whereas Peterson (15) found an average of $64 \%$. Our own data in three species consistently show less than $50 \%$ of the chylomicron cholesterol esterified, and in some instances the values were close to $20 \%$. In the patient and in several rats in which the cholesterol content of cream and corn oil chylomicrons was compared, the percentage ester was twice as high in the cream-fed animals. A similar difference was also reported for dogs (4). It is possible that the small amount of cholesterol contained in the animals fed cream might promote formation of cholesterol ester, since Vahouny and associates (32) found relatively higher percentages of esterified cholesterol in lymph when cholesterol absorption was maximal. Possibly the low percentage of cholesterol ester in chylomicrons when no cholesterol is fed may indicate that, although exogenous cholesterol is largely esterified in the process of absorption, endogenous cholesterol is added to the chylomicron primarily in the unesterified form. Daskalakis and Chaikoff (35), on the other hand, reported no difference in the extent of cholesterol esterification in rats previously maintained on high and low cholesterol diets.

The gas liquid chromatography data on chylomicron constituents agree in most respects with those reported by others $(6,13,15,16,18,40$, 41). The triglycerides resemble closely the fatty acid composition of the dietary fat except for the very short chain fatty acids of cream, which are known to be absorbed by the portal route. However, the triglyceride of membrane isolated by freezing contained a much higher proportion of saturated fatty acids than did the oil phase. This was particularly true in the case of corn oil chylomicrons in which the percentage of saturated fatty acids was nearly four times as high in the membrane fraction as in the oil phase. Such a difference could arise if the membrane triglyceride was synthesized by the intestinal wall as part of a lipoprotein complex that coats the triglyceride droplets traversing the mucosa during fat absorption. It is also possible, however, that the more saturated dietary triglycerides are preferentially adsorbed at an oil-water interface, or that they separate selectively 
from the oil phase of chylomicrons during the isolation of the membrane fractions.

\section{Summary}

Thoracic duct chyle was collected from one patient and several dogs and rats fed corn oil and cream. Washed chylomicrons were frozen and thawed to prepare an oil phase and a membrane fraction. The oil phase contained, in addition to triglyceride, all of the esterified cholesterol, about 25 to $35 \%$ of the free cholesterol, and none of the phospholipid. Chylomicron "ghosts" or "membranes" were demonstrated by electron microscopy in a fraction sedimented by centrifugation. These membranes consisted mostly of phospholipids with small amounts of protein, free cholesterol, and triglyceride. Gas liquid chromatography analysis showed large differences in chylomicron triglyceride fatty acids due to changes in dietary fat, whereas the phospholipid fatty acids were subjected to much less variation. Triglycerides of membranes prepared by freezing contained a much higher proportion of saturated fatty acids than the oil phase. Various interpretations of this finding are discussed. Sphingomyelin from dog chylomicrons contained little or no fatty acids of chain lengths greater than 18 carbons, whereas up to $25 \%$ of dog plasma sphingomyelin fatty acids were of longer chain variety. After cream feeding the percentage of chylomicron cholesterol in the esterified form varied from 32 to $45 \%$, whereas after corn oil feeding the percentage of esterified cholesterol was, except in one instance, between 16 and $33 \%$. Lymph, freed from chylomicrons by centrifugation, showed higher percentages of its cholesterol in the esterified form. On the basis of analytical data it is suggested that chylomicron membrane is a mosaic of small amounts of protein, free cholesterol, and saturated triglyceride in a monolayer of phospholipid.

\section{Acknowledgments}

The author gratefully acknowledges the technical assistance of Jean Briscoe, Nicki Magar, Rita Russell, and Barry Hughes.

\section{References}

1. Dole, V. P., and J. T. Hamlin III. Particulate fat in lymph and blood. Physiol. Rev. 1962, 42, 674.

2. Ashworth, C. T., N. R. Di Luzio, and S. J. Riggi. A morphologic study of the effect of reticuloendo- thelial stimulation upon hepatic removal of minute particles from the blood of rats. Exp. molec. Path. 1963, vol. 2 (suppl. 1), 83.

3. Diluzio, N. R., and S. J. Riggi. The relative participation of hepatic parenchymal and Kupffer cells in the metabolism of chylomicrons. J. reticuloendothel. Soc. 1964, 1, 248.

4. Yokoyama, A., and D. B. Zilversmit. Particle size and composition of dog lymph chylomicrons. J. Lipid Res. 1965, 6, 241.

5. Zilversmit, D. B. Extraction of cholesterol from human serum lipoprotein films. J. Lipid. Res. 1964, 5, 300.

6. Kayden, H. J., A. Karmen, and A. Dumont. Alterations in the fatty acid composition of human lymph and serum lipoproteins by single feedings. J. clin. Invest. 1963, 42, 1373.

7. Minari, O., and D. B. Zilversmit. Use of $\mathrm{KCN}$ for stabilization of color in direct nesslerization of Kjeldahl digests. Analyt. Biochem. 1963, 6, 320.

8. Minari, O., and D. B. Zilversmit. Behavior of dog lymph chylomicron lipid constituents during incubation with serum. J. Lipid Res. 1963, 4, 424.

9. Zak, B., N. Moss, A. J. Boyle, and A. Zlatkis. Reactions of certain unsaturated steroids with acid iron reagent. Analyt. Chem. 1954, 26, 776.

10. Bartlett, G. R. Phosphorus assay in column chromatography. J. biol. Chem. 1959, 234, 466.

11. Van Handel, E., and D. B. Zilversmit. Micromethod for the direct determination of serum triglycerides. J. Lab. clin. Med. 1957, 50, 152.

12. Copius Peereboom, J. W. The analysis of plasticizers by micro-adsorption chromatography. J. Chromatogr. 1960, 4, 323.

13. Karmen, A., M. Whyte, and D. S. Goodman. Fatty acid esterification and chylomicron formation during fat absorption: I. Triglyceride and cholesterol esters. J. Lipid Res. 1963, 4, 312.

14. Morris, M. Measurement of tissue 3-beta-hydroxy sterols by tritiated digitonin. Analyt. Biochem. 1965, 11, 402.

15. Peterson, M. L. The transport of fat in man : a study of chylomicrons. Thesis, Rockefeller Institute, 1960.

16. Nestel, P. J., and R. O. Scow. Metabolism of chylomicrons of differing triglyceride composition. J. Lipid Res. 1964, 5, 46.

17. Newman, H. A. I., C.-T. Liu, and D. B. Zilversmit. Evidence for the physiological occurrence of lysolecithin in rat plasma. J. Lipid Res. 1961, 2, 403.

18. Wood, P., K. Imaichi, J. Knowles, G. Michaels, and L. Kinsell. The lipid composition of human plasma chylomicrons. J. Lipid Res. 1964, 5, 225.

19. Sweeley, C. C. Purification and partial characterization of sphingomyelin from human plasma. J. Lipid Res. 1963, 4, 402.

20. Zilversmit, D. B. A comparison of cream and corn oil chylomicron stability and composition. Fed. Proc. 1964, 23, 501. 
21. Zilversmit, D. B. The structure and composition of lymph chylomicrons. Fed. Proc. 1965, 24, 342.

22. Goodman, D. S. The metabolism of chylomicron cholesterol ester in the rat. J. clin. Invest. 1962, 41, 1886.

23. Wilkins, J. A., H. De Wit, and B. Bronte-Stewart. A proposed mechanism for the effect of different dietary fats on some aspects of cholesterol metabolism. Canad. J. Biochem. 1962, 40, 1091.

24. Kritchevsky, D., and S. A. Tepper. Solubility of cholesterol in various fats and oils. Proc. Soc. exp. Biol. (N. Y.) 1964, 116, 104.

25. Bangham, A. D. Physical structure and behavior of lipids and lipid enzymes in Advances in Lipid Research, R. Paoletti and D. Kritchevsky, Eds. New York, Academic Press, 1963, vol. 1, p. 65.

26. Pinter, G. G., and D. B. Zilversmit. A gradient centrifugation method for the determination of particle size distribution of chylomicrons and of fat droplets in artificial fat emulsions. Biochim. biophys. Acta (Amst.) 1962, 59, 116.

27. Zilversmit, D. B. Centrifugation methods for the study of chylomicrons in Biochemical Problems of Lipids, A. C. Frazer, Ed. Amsterdam, Elsevier, 1963, p. 257.

28. Van Deenen, L. L. M., U. M. T. Houtsmuller, G. H. de Haas, and E. Mulder. Monomolecular layers of synthetic phosphatides. J. Pharm. Pharmacol. 1962, 14, 429.

29. Davies, J. T., and E. K. Rideal. Interfacial Phenomena. New York, Academic Press, 1961, p. 241.

30. Zilversmit, D. B. A method for compressing monomolecular films at oil-water interfaces. J. Colloid Sci. 1963, 18, 794.

31. Dervichian, D. G. The existence and significance of molecular associations in monolayers in Surface Phenomena in Chemistry and Biology, J. F. Danielli, K. G. A. Pankhurst, and A. C. Riddiford, Eds. New York, Pergamon, 1958, p. 70.
32. Vahouny, G. V., I. Fawal, and C. R. Treadwell. Factors facilitating cholesterol absorption from the intestine via lymphatic pathways. Amer. J. Physiol. 1957, 188, 342.

33. Vahouny, G. V., and C. R. Treadwell. Comparative effects of dietary fatty acids and triglycerides on lymph lipids in the rat. Amer. J. Physiol. 1959, 196, 881.

34. Swell, L., E. C. Trout, Jr., J. R. Hopper, H. Field, Jr., and C. R. Treadwell. Mechanism of cholesterol absorption. I. Endogenous dilution and esterification of fed cholesterol-4-C ${ }^{14}$. J. biol. Chem. 1958, 232, 1.

35. Daskalakis, E. G., and I. L. Chaikoff. The significance of esterification in the absorption of cholesterol from the intestine. Arch. Biochem. 1955, 58, 373.

36. Chevallier, F., and M. Vyas. Les origines du cholestérol du chyle mises en évidence a l'aide de la méthode des indicateurs nucléaires. Bull. Soc. Chim. biol. (Paris) 1963, 45, 253.

37. Savary, P., M. J. Constantin, and P. Desnuelle. Sur la structure des triglycerides des chylomicrons lympatiques du rat. Biochim. biophys. Acta (Amst.) 1961, 48, 562.

38. Woo, C. H., and C. R. Treadwell. Lipide changes in chylomicra and subnatant fractions of rat lymph during cholesterol absorption. Proc. Soc. exp. Biol. (N. Y.) 1958, 99, 709.

39. Peters, J. P., and E. B. Man. The nature and formation of thoracic duct chyle. Metabolism 1953, 2, 30.

40. Bragdon, J. H., and A. Karmen. The fatty acid composition of chylomicrons of chyle and serum following the ingestion of different oils. J. Lipid Res. 1960, 1, 167.

41. Whyte, M., A. Karmen, and D. S. Goodman. Fatty acid esterification and chylomicron formation during fat absorption: 2. Phospholipids. J. Lipid Res. $1963,4,322$. 